\title{
Does Ursodeoxycholic Acid Change the Proliferation of the Colorectal Mucosa?
}

\author{
A Randomized, Placebo-Controlled Study \\ Thomas Ochsenkühn ${ }^{a}$ Igor Marstellera Ulrich Hay ${ }^{a}$ Joachim Diebold ${ }^{b}$ \\ Gustav Paumgartner ${ }^{a}$ Burkhard Göke ${ }^{a}$ Michael Sackmann ${ }^{a}$

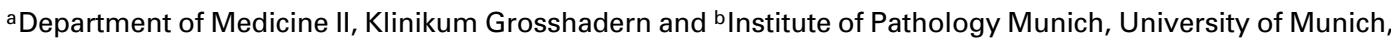 \\ Munich, Germany
}

\section{Key Words}

Bile acids · Bile salts · Ursodeoxycholic acid ·

Deoxycholic acid · Lithocholic acid · Colorectal proliferation - Colorectal mucosa - Colorectal cancer, chemoprevention - Randomized placebo-controlled study

\begin{abstract}
Background: In animal models ursodeoxycholic acid (UDCA) showed a chemoprotective effect against colon cancer. To explain this, a reduced proliferation of the colorectal mucosal proliferation was suggested. We, therefore, examined the influence of UDCA on the proliferation of normal colorectal mucosa in humans. Methods: Following endoscopic polypectomy, 20 patients with colorectal adenomas were randomized to receive either UDCA (750 mg/day, $\mathrm{n}=10$, group $A$ ) or placebo ( $n=10$, group $B$ ) for 6 months in a double-blinded way. Colorectal biopsies were sampled before and at the end
\end{abstract}

This work has been supported by an unrestricted grant from Dr. Falk Pharma, Freiburg, Germany.

\section{KARGER}

Fax +41613061234

E-Mail karger@karger.ch

www.karger.com
(C) 2003 S. Karger AG, Basel

0012-2823/03/0684-0209\$19.50/0

Accessible online at:

www.karger.com/dig of the medication by total colonoscopy. Colorectal mucosal proliferation was measured by FACScan analysis of propidium iodine labeling. Serum was sampled, and serum bile acids were analyzed by gas chromatography. Results: The proliferation rates at the end of the study were similar in both groups (median 15.4\%; range 12.020.9 in group $A$; median $16.0 \%, 14.0-20.2$ in group $B, p=$ 0.41). Serum lithocholic acid levels at the end of the study were significantly higher in group $A(1.3 \mu \mathrm{mol} / \mathrm{l}$, $0.9-1.8)$ than in group $B(0.7 \mu \mathrm{mol} / \mathrm{l}, 0-1.7, \mathrm{p}<0.02)$, whereas serum deoxycholic acid levels were similar in both groups. Conclusions: In this study, UDCA treatment for 6 months does not seem to induce changes in the proliferative behavior of the colorectal mucosa in patients with adenomas. It seems likely that a putative chemopreventive effect of UDCA in humans is not exerted by a reduction of the colorectal proliferation.

Copyright $@ 2003$ S. Karger AG, Basel

\section{Introduction}

The colorectal adenoma-carcinoma sequence [1] provides opportunities for therapeutic interventions to prevent carcinoma development. Dietary interventions as

Thomas Ochsenkühn, MD

Medical Department II, University of Munich, University Hospital Grosshadern DE-81366 Munich (Germany)

Tel. +49897095 0, Fax +498153887981

E-Mail ochsenkuehn@med2.med.uni-muenchen.de 
well as chemopreventive medications have been suggested to suppress or reverse colorectal carcinogenesis. However, the hope that adopting a diet high in fiber, low in fat, and rich in fruits or vegetable could protect against recurrence of colorectal adenomas, was disappointed recently by two large studies [2, 3]. Among chemopreventive medications, non-steroidal anti-inflammatory drugs (NSAIDS), like aspirin, sulindac and cyclo-oxygenase-2 inhibitors, are the best studied agents $[4,5]$. In epidemiological studies, aspirin reduced the incidence of colorectal adenomas and carcinomas [4]. However, lifelong use seems to be necessary and potential side effects of aspirin have to be taken into account [6]. NSAIDs, like sulindac $[7,8]$ and cyclo-oxygenase-2 inhibitors [9], can prevent and regress polyp formation in familial adenomatous polyposis. However, until large clinical trials become available, it remains unclear whether these effects can be extrapolated to sporadic colorectal adenomas.

The bile acid ursodeoxycholic acid (UDCA), the $7 \beta-$ epimer of chenodeoxycholic acid, may be another candidate drug for chemoprevention. In a rat model [10], UDCA fed as food supplement was shown to reduce the incidence of colorectal adenomas and cancers to a greater extent than the NSAID piroxicam. In a similar animal study, UDCA was found to inhibit both the growth of aberrant crypt foci and the development of colon carcinoma [11]. In a retrospective analysis, patients with ulcerative colitis and primary sclerosing cholangitis who had taken UDCA showed a significant decrease in the prevalence of colorectal dysplasia as compared to the control group [12].

The postulated chemopreventive mechanism of UDCA is still unclear. In animal models, UDCA could lower the fecal contents and concentrations of the secondary bile acid deoxycholic acid [13-15], which has co-carcinogenic [16] potential in colorectal cancer [17]. In patients with colorectal adenomas the levels of deoxycholic acid in serum correlated with the proliferation rates of the colorectal mucosa [18]. Hyperproliferation is regarded as an early step in colorectal carcinogenesis [19, 20, 48]. Thus, we tested the hypothesis that UDCA exerts its putative chemoprotective effect by decreasing the proliferation rate of the colorectal mucosa. In addition, the bile acid concentrations in serum were determined before and at the end of the study medication.

\section{Methods}

Patient Evaluation: Criteria of Inclusion

Patients who were referred to our endoscopy unit for a follow-up colonoscopy after endoscopic resection of colorectal adenomas were eligible for inclusion. Patients with malignancies, inflammatory bowel diseases, liver disease [21], reduced state of health, obesity (BMI $>30$ ), on a special diet, or with a family history of cancer, were excluded. 34 consecutive patients were eligible to be included in the study. Of these, 29 agreed to participate.

\section{Randomization Procedure and Study Medication}

In chronological order of their appearance the patients received closed envelopes containing numbers. These numbers had randomly been attributed to either UDCA or placebo medication assigned in identical blisters and in a mode of 1 to 1 . This study medication was supplied by Dr. Falk Pharma GmbH (Freiburg, Germany): In the verum group (group A), UDCA was given orally in a dose of $750 \mathrm{mg} /$ day, according to $13-15 \mathrm{mg} / \mathrm{kg}$ body weight. The placebo capsules for the control group (group B) were of identical shape and contained lactose.

\section{Endoscopy and Biopsy}

In both study groups, total colonoscopy was performed by the same group of experienced endoscopists using standard colonoscopes. Endoscopy was performed at study entry before the study medication was started, and after 6 months while study medication was still taken by the patients.

During each endoscopy, six biopsy specimens from an adjacent area of about $4 \mathrm{~cm}^{2}$ were obtained from each segment of the colon (cecum, ascending, transverse, descending and sigmoid colon, rectum). Three of the respective specimens were instantly deep frozen, using liquid nitrogen. Two of the respective specimen were placed in a medium (DPBS, Sigma, Germany) containing penicillin and streptomycin. These samples were kept at room temperature and transferred to the laboratory within $15 \mathrm{~min}$. The remaining biopsy was placed in formalin and examined by routine histopathology.

Tissue Preparation and Flow Cytometry (FACS)

Two biopsies from each segment were prepared independently and separately. Nuclei from the mucosal cells were obtained by applying a modification [18] of previously published techniques [22$27,49]$. In brief, after washing three times, tissue samples were homogenized in a glass hand potter using $2 \mathrm{ml}$ buffer $(0.1 \mathrm{~mol} / 1$ citric acid, $0.5 \%$ Tween 20 ). The suspension was then agitated at $37^{\circ} \mathrm{C}$ for $20 \mathrm{~min}$, and sonicated for $3 \mathrm{~min}$. The homogenate was then centrifuged at $40 \mathrm{~g}$, the supernatant resuspended and centrifuged at $1,700 \mathrm{~g}$ to isolate cell nuclei. The nuclei pellet was resuspended in $2 \mathrm{ml}$ cold $\left(4{ }^{\circ} \mathrm{C}\right) \mathrm{DPBS}$, centrifuged for $10 \mathrm{~min}$ at $1,950 \mathrm{~g}$, resuspended and incubated in $2 \mathrm{ml}$ DPBS, containing $0.1 \%$ Triton, at room temperature for $10 \mathrm{~min}$. The nuclei were then centrifuged at $1,950 \mathrm{~g}$ and fixed in $70 \%$ ethanol at $-30^{\circ} \mathrm{C}$ for at least 7 days until measurement.

Immediately before flow cytometric analysis, nuclei were stained by incubation with propidium iodide $(50 \mu \mathrm{g} / \mathrm{ml})$ in the dark for $30 \mathrm{~min}$ at $4{ }^{\circ} \mathrm{C}$. The two nuclei suspensions from each colorectal segment were then filtered through a $50-\mu \mathrm{m}$ nylon mesh and assayed $\left(50,000\right.$ nuclei analyzed) using a FACScan ${ }^{\mathrm{TM}}$ flow cytometer (Becton Dickinson, Heidelberg, Germany) equipped with a doublet discrimination module using the CellFit ${ }^{\mathrm{TM}}$ software [28]. 
The proliferation rate was calculated as the fractional number of cells with a DNA content corresponding to the $S$ and $G_{2} M$ phases of the cell cycle $[50,51]$. The overall proliferation rate was calculated as the mean proliferative index of two samples of all six individual segments: cecum, ascending, transverse, descending, and sigmoid colon and rectum, respectively. Human blood lymphocytes were used as internal standard [28].

\section{Histology}

One of the six biopsies of each segment was examined histologically, to ensure that no signs of inflammation or infiltration by blood cells were present, and to avoid falsely elevated proliferation rates in flow cytometry. The histological examination was performed by a histopathologist who was unaware of the endoscopic diagnosis and the results of flow cytometry.

\section{Blood Sampling}

Fasting blood samples were collected prior to preparation for each of the two colonoscopies, that is at the beginning of the study and at the end of the study period. Blood collections were performed between 08:00 and 10:00 $\mathrm{h}$ and subsequently serum was obtained through centrifugation.

\section{Determination of Bile Acid Concentration}

Two milliliters of serum were extracted on Bond Elut C-18 cartridges [29, 30] (Analytichem International, Harbor City, Calif., USA). The bile acids were eluted with $6 \mathrm{ml}$ of $75 \%$ methanol. The eluate was cleaned with 3 volumes of $n$-hexane after acidification to a $\mathrm{pH}$ of 3.5. Bile acids were solvolysed and then deconjugated enzymatically [31]. The deconjugated bile acids were eluted with $10 \mathrm{ml}$ of $75 \%$ methanol according to the method of Setchell and Matsui [32]. The deconjugated bile acids were then passed through a Lipidex1000 column [32] (Packard Instrument Co., Downers Grove, Ill., USA) and eluted with $10 \mathrm{ml}$ of $75 \%$ methanol. The bile acids were then methylated and trimethylsilylated. The methylester trimethylsilylate-ether derivates were dried and dissolved in $25 \mu \mathrm{l}$ isooctane, and 1-2 $\mu \mathrm{l}$ were analyzed by capillary gas chromatography. A gas chromatograph (Varian 3700, Varian, Palo Alto, Calif., USA) and a 25-m $\times$ 0.32-mm fused silica capillary OV-1701 column (CP-Sil-19SB; Chrompack, Middleburg, The Netherlands) were used for bile acid separation [30,33]. Samples were introduced by cold on-column injection, and individual bile acids were separated by temperature programming [30]. The initial on-column injection temperature was $140^{\circ} \mathrm{C}$ with a heating rate of $5^{\circ} \mathrm{C} / \mathrm{min}$ and a maximum temperature of $265^{\circ} \mathrm{C}$, which was held for $8 \mathrm{~min}$. Quantification of bile acids was carried out using hyodeoxycholic acid as an internal standard. To ensure a constant recovery of the individual bile acids, a reference serum was analyzed with each batch of serum samples.

\section{Statistical Analysis}

Sample size calculation was based on data of our previous study, in which we analyzed the proliferation rate of the normal mucosa in a population with colorectal adenomas [18]. In that study the proliferation rate was $13.7 \pm 2.5 \%$ (mean $\pm \mathrm{SD}$ ), ranging from 10 to $18.7 \%$. We assumed that, in order to show a clinically relevant effect, UDCA should be able to lower the proliferation rate to the lowest quintile, i.e. a decrease of $1 / 4$ from the mean.

Applying SPSS for Windows (SPSS Inc., Chicago, Ill., USA) and using a two-tailed t-test with an $\alpha$ value of $0.05,10$ patients per group were required to yield a statistical power of more than $80 \%$. For sta-
Table 1. Age, weight, sex and drug distribution of all patients

\begin{tabular}{rllll}
\hline Patient & $\begin{array}{l}\text { Age } \\
\text { years }\end{array}$ & $\begin{array}{l}\text { Weight } \\
\mathrm{kg}\end{array}$ & Sex & Medication \\
\hline 1 & 61 & 74 & $\mathrm{M}$ & Placebo \\
2 & 54 & 83 & $\mathrm{M}$ & Placebo \\
3 & 58 & 73 & $\mathrm{M}$ & UDCA \\
4 & 58 & 74.5 & $\mathrm{M}$ & Placebo \\
5 & 55 & 70 & $\mathrm{~F}$ & UDCA \\
6 & 51 & 78 & $\mathrm{~F}$ & UDCA \\
7 & 57 & 72 & $\mathrm{~F}$ & UDCA \\
8 & 77 & 69.5 & $\mathrm{M}$ & UDCA \\
9 & 65 & 75 & $\mathrm{~F}$ & Placebo \\
10 & 60 & 100 & $\mathrm{~F}$ & Placebo \\
11 & 55 & 78 & $\mathrm{M}$ & UDCA \\
12 & 59 & 74 & $\mathrm{M}$ & Placebo \\
13 & 63 & 90 & $\mathrm{M}$ & Placebo \\
14 & 71 & 76 & $\mathrm{M}$ & UDCA \\
15 & 61 & 78 & $\mathrm{M}$ & UDCA \\
16 & 63 & 85 & $\mathrm{M}$ & Placebo \\
17 & 58 & 82 & $\mathrm{M}$ & Placebo \\
18 & 56 & 87.5 & $\mathrm{M}$ & UDCA \\
19 & 62 & 82 & $\mathrm{M}$ & UDCA \\
20 & 66 & 80 & $\mathrm{M}$ & Placebo \\
\hline
\end{tabular}

tistical determination of the proliferation rates, we analyzed the proliferation rates of each of the six colorectal segments and then calculated the statistical mean. A two-sided linear correlation testing (Pearson) was used, a $\mathrm{p}$ value $<0.05$ was regarded as statistically significant.

\section{Ethics}

The study complied with the Declaration of Helsinki. It was approved by the Ethics Committee of the Medical Faculty of the University of Munich. Informed consent was obtained from all patients.

\section{Results}

\section{Patient Characteristics}

Of the 34 consecutive patients who were asked to participate, 29 agreed and were evaluated. Due to technical reasons, the biopsies of 2 patients, 1 in each group, could not be examined. Seven patients decided to end the study prematurely after 3-6 weeks. Two for epigastric discomfort and 1 without specific reasons in group A, 2 for epigastric discomfort and another 2 without specific reasons in group B. Hence, complete data were obtained in 20 of the 29 patients, 10 in each group. The main patient characteristics are shown in table 1 . In group A with 3 women and 7 men, the median age was 56.5 years, ranging from 


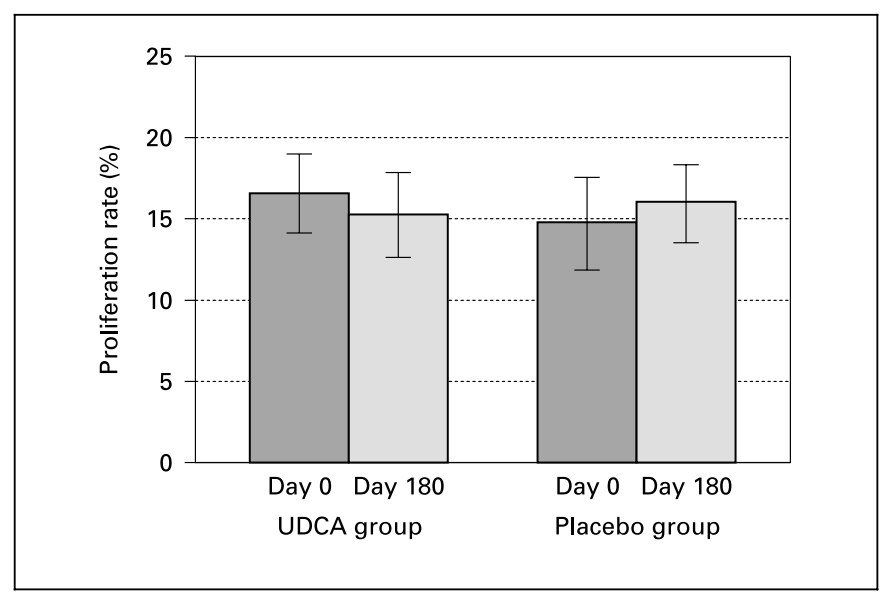

Fig. 1. Median colorectal proliferation for the UDCA and placebo group, before (day 0) and after treatment (day 180). Bars indicate the related SD. Differences were not significant.

Table 2. Median proliferation rates (ranges) in UDCA group A and placebo group B before and at the end of treatment (180 days). The respective results showed no significant differences within the groups

\begin{tabular}{lcc}
\hline Proliferation rate, \% & Before treatment & End of treatment \\
\hline Group A & $16.6(13.2-20.5)$ & $15.4(12.0-20.9)$ \\
Group B & $14.9(11.9-20.6)$ & $16.0(14.0-20.2)$ \\
\hline
\end{tabular}

51 to 77 (n.s.), and the median weight was $77 \mathrm{~kg}$, ranging from 70 to 88 (n.s.). In group B, 2 women and 8 men, the median age was 60.5 years, ranging from 54 to 66 (n.s.), and the median weight was $81 \mathrm{~kg}$, ranging from 74 to $100 \mathrm{~kg}$ (n.s.).

\section{Pathology}

In 2 patients of group A and in 3 patients of group B, polyps $<5 \mathrm{~mm}$ were found and were removed during the first colonoscopy. Histologically, polyps were either hyperplastic polyps or tubular adenomas. No newly diagnosed polyps were found during the second colonoscopy in either of the groups. In all patients, the histological analysis of the (control) biopsies of endoscopically normal colorectal mucosa revealed no signs of inflammation, cellular infiltration, dysplasia, no adenomatous or malignant growth, and no aberrant crypt foci.

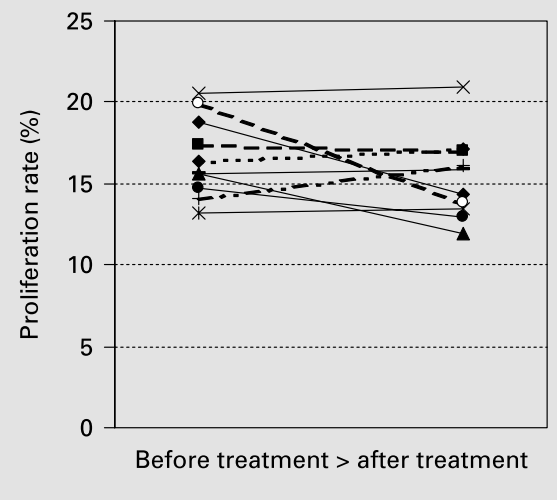

Patient No.:
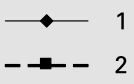

$\checkmark-3$

$-\infty-4$

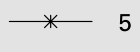

$\longrightarrow 6$

$-\cdot+-7$

$\times \quad 8$

\begin{tabular}{rr}
- & \\
\hdashline$\ldots$ & 10
\end{tabular}

Fig. 2. Effect of a 6-month lasting UDCA treatment on the individual mean colorectal proliferation.

\section{Proliferation}

As determined by FACS, the median proliferation rate in group A (treatment with UDCA) was $16.6 \%$ (range 13.2-20.5) before treatment and 15.4\% (range 12.0-20.9) after treatment. The median proliferation rate in the control group (B) was $14.9 \%$ (range 11.9-20.6) before treatment and 16.0\% (range 14.0-20.2) after treatment. Having analyzed the set of 240 probes ( 20 patients, 6 segments, 2 samples), the coefficient of variation was $1.34 \%$ for nuclei in the $\mathrm{G}_{0} / \mathrm{G}_{1}$ fraction, $10.3 \%$ for the $\mathrm{S}$ fraction, and $7.9 \%$ for the $\mathrm{G}_{2} / \mathrm{M}$ fraction.

The median proliferation rates reveal no significant differences within the groups (group A: $\mathrm{p}=0.39$, and group B: $p=0.24$ ) and between the groups (before treatment: $p=0.11$, and end of treatment: $p=0.41$ ); these data are demonstrated in table 2 and figure 1 . The individual proliferation rates for each patient of the UDCA group (A) and the placebo group (B) - before and after the treatment - are shown in figure 2 (for UDCA) and figure 3 (for placebo).

\section{Serum Bile Acids}

The serum bile acid concentrations are summarized in table 3. In group A, the median UDCA serum levels increased from $1.5 \mu \mathrm{mol} / 1$ (range 0-5.7) before starting the treatment to $13.2 \mu \mathrm{mol} / 1$ (range 1.6-33.4) after 6 months of therapy $(\mathrm{p}<0.02)$. In contrast, the median UDCA serum levels in group B did not differ significantly before $(0.9 \mu \mathrm{mol} / 1$, range $0-3.1)$ and after 6 months of therapy $(1.2 \mu \mathrm{mol} / 1$, range $0-2.6)$. There were no significant differences in the median UDCA baseline levels

\footnotetext{
$\overline{212} \quad \overline{\text { Digestion 2003;68:209-216 }}$
} 


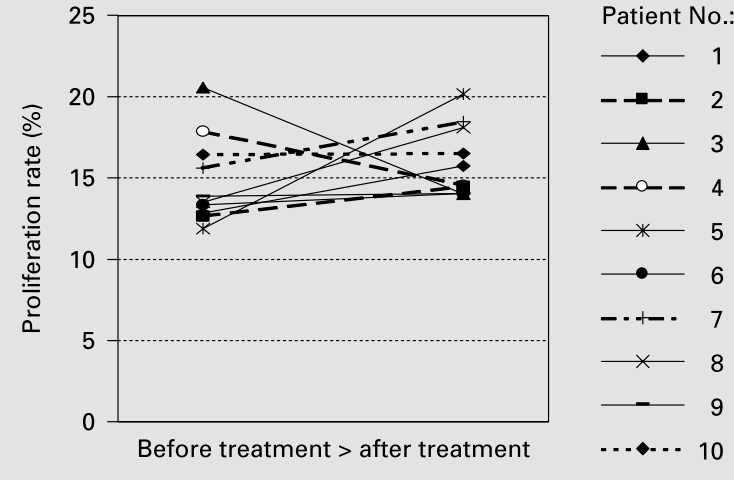

Fig. 3. Individual mean colorectal proliferation in the control group.

Table 3. Median serum bile acid concentrations (ranges) in UDCA group A and placebo group B before and at the end of treatment (180 days)

\section{Before treatment End of treatment}

\begin{tabular}{lll}
\hline$U D C A, \mu \mathrm{mol} / \mathrm{l}$ & & \\
Group A & $1.5(0.0-5.7)$ & $13.2(1.6-33.4)^{*}$ \\
Group B & $0.9(0.0-3.1)$ & $1.2(0.0-2.6)^{*}$ \\
\hline
\end{tabular}

\begin{tabular}{lll}
\hline Deoxycholic acid, $\mu$ mol/l & \\
Group A & $1.7(0.0-2.4)$ & $2.4(1.2-3.9)^{+}$ \\
Group B & $2.2(0.0-6.3)$ & $1.8(0.0-3.8)^{+}$
\end{tabular}

Lithocholic acid, $\mu \mathrm{mol} / \mathrm{l}$

$\begin{array}{lll}\text { Group A } & 1.4(0.0-3.8) & 1.3(0.9-1.8)^{* *} \\ \text { Group B } & 0.9(0.0-1.74) & 0.7(0.0-1.7)^{* *}\end{array}$

\begin{tabular}{lcc}
\hline Chenodeoxycholic acid, $\mu$ mol/l & \\
Group A & $2.6(0.8-5.8)$ & $3.2(0.9-10.3)^{+}$ \\
Group B & $3.2(0.64-11.2)$ & $2.3(0.72-6.2)^{+}$ \\
\hline Cholic acid, $\mu \mathrm{mol} / \mathrm{l}$ & & \\
Group A & $1.5(0.7-3.8)$ & $1.5(0.8-3.7)^{+}$ \\
Group B & $1.5(0.8-4.9)$ & $1.2(0.7-2.3)^{+}$
\end{tabular}

$* \mathrm{p}<0.001 ; * * \mathrm{p}<0.02 ;{ }^{+}$n.s.

between groups A and B ( 1.5 vs. $0.9 \mu \mathrm{mol} / \mathrm{l})$. The median UDCA serum levels at the end of the study were significantly higher in group A (13.2 $\mu \mathrm{mol} / \mathrm{l}$, range 1.6-33.4) than in group $B(1.2 \mu \mathrm{mol} / 1$, range $0-2.6, \mathrm{p}<0.001)$.

The median serum levels of deoxycholic acid at the end of the treatment period were similar in group $\mathrm{A}(2.4 \mu \mathrm{mol} / \mathrm{l}$, range 1.2-3.9) and group $B(1.8 \mu \mathrm{mol} / 1$, range $0-3.8, \mathrm{p}=$ $0.23)$. The median lithocholic acid levels at the end of the study were significantly higher in group A $(1.3 \mu \mathrm{mol} / 1$, range $0.9-1.8)$ than in group $\mathrm{B}(0.7 \mu \mathrm{mol} / 1$, range $0-1.7$, $\mathrm{p}<0.02)$.

The coefficients of variation of the individual bile acids in the reference serum were $6.3 \%$ for lithocholic acid, $4.8 \%$ for deoxycholic acid, 5.3\% for cholic acid, $5.7 \%$ for chenodeoxycholic acid, and 5.9\% for UDCA.

\section{Discussion}

The results of this study indicate that an oral therapy of $750 \mathrm{mg}$ UDCA per day over 6 months does not change the proliferation of the colorectal mucosa in patients with adenomas. Already in 1987, Deschner et al. [34] examined the rectal mucosa of patients under UDCA for gallstone dissolution therapy. They also found an unaltered proliferation rate of the rectal mucosa after 9 months of therapy [34]. In vitro studies showed that incubating cells of different tumor cell lines with UDCA inhibited cell proliferation [35]. However, animal experiments in rats showed the opposite: UDCA feeding even lead to mild hyperproliferation of the basal crypt cells in the colon, which the authors regarded as a compensatory response to superficial cell damage [36]. According to our data, a potential chemoprotective effect of UDCA for the human colon does not result from a change in the proliferative behavior.

The other main finding of our study is that UDCA does not lead to a decrease of serum deoxycholic acid levels, although previous animal studies [13, 14] had observed a reduction of the fecal deoxycholic acid under UDCA therapy. Since serum levels of deoxycholic acid correlate with deoxycholic acid concentrations in stool [37], we conclude that in man UDCA does not decrease fecal deoxycholic acid concentrations. This conclusion is supported by the recent finding of van Gorkom et al. [38] who found that in healthy volunteers, orally given UDCA does not decrease fecal deoxycholic acid concentrations.

The lack of effect of UDCA on deoxycholic acid levels is consistent with the lack of effect on the colorectal proliferation rate. It had been hypothesized that UDCA inhibits colorectal carcinogenesis by lowering the concentration of the co-carcinogenic [16] secondary bile acid deoxycholic acid [13, 39]. Increased levels of deoxycholic acid are found in the feces [40] and the serum [41] of patients with colorectal adenomas. Deoxycholic acid can lead to nuclear damage of colonic cells in carcinogen-induced 
animals [42], and higher deoxycholic acid levels were associated with higher mucosal proliferation rates in animal [43] and in human studies [18]. In addition, a direct stimulating effect of low-dose deoxycholate on colon cancer cell proliferation in vitro was reported recently [52]. Hence, it was postulated that UDCA lowers the colorectal proliferation rate and cell turnover and thus could decrease the formation of adenomatous or dysplastic lesions [14]. Considering our data, however, this hypothesis seems rather unlikely.

Since in one study the taurin-conjugated UDCA (tauroursodeoxycholic acid) protected human colonic cancer cell lines from cytotoxic effects of hydrophobic bile acids, whereas the unconjugated UDCA did not alter short-term cytotoxicity of any bile acid [53], a potential benefit of UDCA through conjugation has to be taken into account.

Another explanation for the lack of effect of UDCA on colorectal proliferation could be that the other co-carcinogenic secondary bile acid, lithocholic acid, did significantly increase in the UDCA group as compared to the control group. Like deoxycholic acid, also lithocholic acid concentrations correlated with the extent of cell proliferation in the colorectal mucosa of patients with colorectal cancer or adenomatous polyps [40]. The lithocholate/deoxycholate ratio in feces has been found increased in patients at high risk for colorectal cancer and has been proposed to be of diagnostic value [44]. The increase of fecal lithocholic acid concentrations under UDCA therapy was also observed in an animal model [14] and recently confirmed in man in the paper of Van Gorkom et al. [38].

Interestingly, if a sulfated conjugate of UDCA was fed to the animals, fecal lithocholic acid concentrations were reduced even in comparison to control animals [14]. The sulfation prevents biotransformation of UDCA to lithocholic acid, and increases hydrophilicity of the UDCA molecule, thus preventing intestinal absorption [14]. The authors' conclusion that the sulfated UDCA may be a more effective chemoprotective agent than normal UDCA should lead to a future study using this modified drug.

The mechanism by which UDCA inhibits colorectal carcinogenesis in animal experiments remains unclear. Furthermore, it is questionable whether it has a chemopreventive effect in humans at all. Two recent human studies have been published suggesting a possible chemopreventive effect of UDCA on colorectal cancer. The first one includes a non-randomized small cohort that was followed for an unspecified period of time: patients with ulcerative colitis and primary sclerosing cholangitis who had taken UDCA, showed a decrease in the prevalence of colorectal dysplasias [12]. However, this study had several limitations [45]. One major point of criticism is the surprisingly high rate of dysplasia and cancer in patients not treated with UDCA, namely $72 \%$, after a mean of 21 years. So far, rates of $20-50 \%$ after $20-25$ years of duration of ulcerative colitis have been reported in the literature $[16,46,47]$. This discrepancy casted doubt on whether their findings are applicable to unselected patients with ulcerative colitis and primary sclerosing cholangitis [45].

The other observational study from Serfaty et al. [54] describes 52 patients with primary biliary cirrhosis who had taken UDCA for $45.6 \pm 27.6$ months: as compared to the control group $(n=62)$, patients with UDCA medication for primary biliary cirrhosis had a significantly lower adenoma recurrence rate after removal. Moreover, a significant reduction of the colonic epithelial proliferation was observed in patients treated with UDCA (compared to the control patients). Although these results seem to be convincing, again some study limitations have to be mentioned. Unfortunately, the study was not blinded and the participating patients had a severe liver disease. The number of patients differed between the groups and the patients were - in contrast to the gender prevalence of sporadic adenomas - mostly women. The colonic epithelial proliferation was determined by anti-Ki-67 antibodies only in a subgroup of patients: 10 treated versus 2 untreated patients. The respective biopsies represented only the middle part of the colon; cecum, sigma and rectum were left out [54].

Compared to our approach, one advantage of this study is the about seven times longer UDCA treatment period; a long-lasting drug application seems to be necessary for colorectal cancer chemoprevention in general [55]. The authors conclude that randomized studies are needed for the repeated evaluation of UDCA in colorectal cancer prevention [54].

The only clear evidence of a chemopreventive effect of UDCA comes from animal studies [10, 11]. Considering our finding of an unchanged deoxycholic acid level under UDCA therapy in man and the finding of decreased deoxycholic acid levels in comparable animal experiments, it might as well be possible that animals are different to humans with regard to their intestinal bile acid metabolism. For that reason, the potential chemopreventive effect of UDCA may not be reproducible in man. The postulated effect may also require a longer treatment period, if there is an effect at all. This is currently being evaluated in a phase III trial at the University of Arizona (USA), analyzing adenoma recurrence in patients with sporadic adenomas [4]. The data arising from that study will hope- 
fully shed more light on the role of UDCA in chemoprevention of colorectal cancer.

Until today, UDCA cannot be recommended as a colorectal cancer chemoprevention. Moreover, the hypothesized chemopreventive effect of UDCA in humans seems to be exerted by a mechanism other than a change in the proliferative behavior of the colorectal mucosa.

\section{Acknowledgement}

The authors would like to thank Dr. Ulrich Beuers for the excellent scientific and technical support in his laboratory.

\section{References}

1 Vogelstein B, Fearon ER, Hamilton SR, Kern SE, Preisinger AC, Leppert M, Nakamura Y, White R, Smits AM, Bos JL: Genetic alterations during colorectal-tumor development. N Engl J Med 1988;319:525-532.

2 Alberts DS, Martinez ME, Roe DJ, GuillenRodriguez JM, Marshall JR, van Leeuwen JB, Reid ME, Ritenbaugh C, Vargas PA, Bhattacharyya AB, Earnest DL, Sampliner RE: Lack of effect of a high-fiber cereal supplement on the recurrence of colorectal adenomas. Phoenix Colon Cancer Prevention Physicians' Network. N Engl J Med 2000;342:1156-1162.

3 Schatzkin A, Lanza E, Corle D, Lance P, Iber F, Caan B, Shike M, Weissfeld J, Burt R, Cooper MR, Kikendall JW, Cahill J: Lack of effect of a low-fat, high-fiber diet on the recurrence of colorectal adenomas. Polyp Prevention Trial Study Group. N Engl J Med 2000;342:1149_ 1155.

4 Gwyn K, Sinicrope FA: Chemoprevention of colorectal cancer. Am J Gastroenterol 2002;97: 13-21.

5 Ricciardiello L, Roda E, Bazzoli F: Chemoprevention in colorectal neoplasias: What is practical and feasible? Dig Dis 2002;20:70-72.

6 Cryer B, Feldman M: Effects of very low dose daily, long-term aspirin therapy on gastric, duodenal and rectal prostaglandin levels and on mucosal injury in healthy humans. Gastroenterology 1999;117:17-25.

7 Giardiello FM, Hamilton SR, Krush AJ, Piantadosi S, Hylind LM, Celano P, Booker SV, Robinson CR, Offerhaus GJ: Treatment of colonic and rectal adenomas with sulindac in familial adenomatous polyposis. N Engl J Med 1993;328:1313-1316.

8 Cruz-Correa M, Hylind LM, Romans KE, Booker SV, Giardiello FM: Long-term treatment with sulindac in familial adenomatous polyposis: A prospective cohort study. Gastroenterology 2002;122:641-645.

9 Steinbach G, Lynch PM, Phillips RK, Wallace MH, Hawk E, Gordon GB, Wakabayashi N, Saunders B, Shen Y, Fujimura T, Su LK, Levin $\mathrm{B}$ : The effect of celecoxib, a cyclooxygenase-2 inhibitor, in familial adenomatous polyposis. N Engl J Med 2000;342:1946-1952.

10 Earnest DL, Holubec H, Wali RK, Jolley CS Bissonette M, Bhattacharyya AK, Roy $\mathrm{H}$, Khare S, Brasitus TA: Chemoprevention of azoxymethane-induced colorectal carcinogenesis by supplemental dietary ursodeoxycholic acid. Cancer Res 1994;54:5071-5074.
11 Narisawa T, Fukaura Y, Terada K, Sekiguchi $\mathrm{H}$ : Inhibitory effects of ursodeoxycholic acid on N-methylnitrosourea-induced colon carcinogenesis and colorectal mucosal telomerase activity in F344 rats. J Exp Clin Cancer Res 1999; 18:259-266.

12 Tung BY, Emond MJ, Haggitt RC, Bronner MP, Kimmey MB, Kowdley KV, Brentnall TA: Ursodiol use is associated with lower prevalence of colorectal neoplasia in patients with ulcerative colitis and primary sclerosing cholangitis. Ann Intern Med 2001;134:89-95.

13 Kurtz WJ, Guldutuna S, Leuschner U: Differing effect of chenodeoxycholic acid and ursodeoxycholic acid on bile acids in rat colorectal wall and contents. Tokai J Exp Clin Med 1988; 13:91-97.

14 Rodrigues CM, Kren BT, Steer CJ, Setchell KD: The site-specific delivery of ursodeoxycholic acid to the rat colon by sulfate conjugation. Gastroenterology 1995;109:1835-1844.

15 Batta AK, Salen G, Holubec H, Brasitus TA, Alberts D, Earnest DL: Enrichment of the more hydrophilic bile acid ursodeoxycholic acid in the fecal water-soluble fraction after feeding to rats with colon polyps. Cancer Res 1998;58: 1684-1687.

16 Brentnall TA, Haggitt RC, Rabinovitch PS, Kimmey MB, Bronner MP, Levine DS et al: Risk and natural history of colonic neoplasia in patients with primary sclerosing cholangitis and ulcerative colitis. Gastroenterology 1996; 110:331-338.

17 Reddy BS, Narasawa T, Weisburger JH, Wynder EL: Promoting effect of sodium deoxycholate on colon adenocarcinomas in germ-free rats. J Natl Cancer Inst 1976;56:441-442.

18 Ochsenkühn T, Bayerdörffer E, Meining A, Schinkel M, Thiede C, Nüssler V, Sackmann M, Hatz R, Neubauer A, Paumgartner G: Colonic mucosal proliferation is related to serum deoxycholic acid levels. Cancer 1999;85:16641669.

19 Lipkin M: Biomarkers of increased susceptibility to gastrointestinal cancer: New application to studies of cancer prevention in human subjects. Cancer Res 1988;48:235-245.

20 Fearon ER, Vogelstein B: A genetic model for colorectal tumorigenesis. Cell 1990;61:759767.

21 Mannes GA, Stellaard F, Paumgartner G: Diagnostic sensitivity of fasting and postprandial serum bile acids determined by different methods. Clin Chim Acta 1987;162:147-154.
22 Fischbach W, Zidianakis Z, Lüke G, Kirchner T, Mössner J: DNA mapping of colorectal neoplasms: A flow cytometric study of DNA abnormalities and proliferation. Gastroenterology 1993;105:1126-1133.

23 Bortoluzzi F, Valentini M, Cernigoi C, Toffoli $\mathrm{G}$, Boiocchi $\mathrm{M}$, Poletti $\mathrm{M}$ et al: DNA flow cytometric evaluation of cell cycle distribution in ulcerative colitis: A proposed method for assessing severity of disease. Gut 1995;36:50 54.

24 Hartmann DP, Montgomery EA, Carr NJ Gupta PK, Azumi N: Flow cytometric DNA analysis of ulcerative colitis using paraffinembedded biopsy specimens: Comparison with morphology and DNA analysis of fresh samples. Am J Gastroenterol 1995;90:590-596.

25 Nishida K, Takano H, Yoneda M, Ohtsuki T, Fujii M, Teresawa Y et al: Flow cytometric analysis of nuclear DNA content in tissues of colon cancer using endoscopic biopsy specimens. J Surg Oncol 1995;59:181-185.

26 Pasricha PJ, Bedi A, O’Connor K, Rashid A, Akktar AJ, Zahurak ML et al: The effects of sulindac on colorectal proliferation and apoptosis in familial adenomatous polyposis. Gastroenterology 1995;109:994-998.

27 Porschen R, Robin U, Schumacher A, Schauseil S, Borchard F, Hengels KJ et al: DNA aneuploidy in Crohn's disease and ulcerative colitis: Results of a comparative flow cytometric study. Gut 1992;33:663-667.

28 Bach BA, Knape WA, Edinger MG, Tubbs RR: Improved sensitivity and resolution in the flow cytometric DNA analysis of human solid tumor specimen. Am J Clin Pathol 1991;96:615627.

29 Setchell KDR, Ives JA, Cashmore GC, Lawson AM: On the homogeneity of stools with respect to bile acid composition and normal day-to-day variations: A detailed qualitative and quantitative study using capillary column gas chromatography-mass spectrometry. Clin Chim Acta 1987;162:257-275.

30 Stellaard F, Sackmann M, Sauerbruch T, Paumgartner G: Simultaneous determination of cholic acid and chenodeoxycholic acids pool sizes and fractional turnover rates in human serum using ${ }^{13} \mathrm{C}$-labelled bile acids. J Lipid Res 1984;25:1313-1319.

31 Karlaganis G, Paumgartner G: Determination of bile acids in serum by capillary gas-liquid chromatography. Clin Chim Acta 1979;92:1926. 
32 Setchell KDR, Matsui A: Serum bile acid analysis. Clin Chim Acta 1982;127:1-17.

33 Stellaard F, Paumgartner G: Measurement of isotope ratios in organic compounds at picomole quantities by capillary gas chromatography/quadrupole electron impact mass spectometry. Biomed Mass Spectrom 1985;12: 560-564.

34 Deschner EE, Hallak A, Rozen P, Gilat T: Prolonged administration of bile salts for gallstone dissolution and its effect on rectal epithelial cell proliferation. Dig Dis Sci 1987;32:991-996.

35 Martinez JD, Stratagoules ED, LaRue JM, Powell AA, Gause PR, Craven MT, Payne CM, Powell MB, Gerner EW, Earnest DL: Different bile acids exhibit distinct biological effects: The tumor promoter deoxycholic acid induces apoptosis and the chemopreventive agent ursodeoxycholic acid inhibits cell proliferation. Nutr Cancer 1998;31:111-118.

36 Simanowski UA, Seitz HK, Czygan P, Horner M, Waldherr R, Weber E, Kommerell B: Chronic ursodeoxycholic acid- and chenodeoxycholic acid-feeding-induced changes of colon mucosal cell proliferation in rats. J Natl Cancer Inst 1987;79:163-166.

37 Van Faassen A, Ochsenkühn T, Houterman S, van der Ploeg EM, Bueno-de-Mesquita BH, Ocke MC, Bayerdörffer E, Janknegt RA: Plasma deoxycholic acid is related to deoxycholic acid in faecal water. Cancer Lett 1997;114: 293-294.

38 Van Gorkom BA, van der Meer R, Boersmavan Ek W, Termont DS, de Vries EG, Kleibeuker JH: Changes in bile acid composition and effect on cytolytic activity of fecal water by ursodeoxycholic acid administration: A placebo-controlled cross-over intervention trial in healthy volunteers. Scand J Gastroenterol 2002;37:965-971
39 Beuers U, Spengler U, Zwiebel FM, Pauletzki J, Fischer S, Paumgartner G: Effect of ursodeoxycholic acid on the kinetics of the major hydrophobic bile acids in health and chronic cholestatic liver disease. Hepatology 1992;15: 603-608.

40 Stadler J, Yeung KS, Furrer R, Marcon N, Himal HS, Bruce WR: Proliferative activity of rectal mucosa and soluble fecal bile acids in patients with normal colons and in patients with colorectal polyps or cancer. Cancer Lett 1988;38:315-320.

41 Bayerdörffer E, Mannes GA, Richter WO, Ochsenkühn T, Wiebecke B, Köpcke W, Paumgartner G: Increased serum deoxycholic acid levels in men with colorectal adenomas. Gastroenterology 1993;104:145-151.

42 Suzuki K, Bruce WR: Increase by deoxycholic acid of the colonic nuclear damage induced by known carcinogens in C57BL/6J mice. J Natl Cancer Inst 1986;76:1129-1132.

43 Hori T, Matsumoto K, Sakaitani Y, Sato M, Morotomi M: Effect of dietary deoxycholic acid and cholesterol on fecal steroid concentration and its impact on the colonic crypt cell proliferation in azoxymethane-treated rats. Cancer Lett 1998;124:79-84.

44 Owen RW, Thompson MH, Hill MJ, Wilpart M, Mainguet P, Roberfroid M: The importance of the ratio of lithocholic to deoxycholic acid in large bowel carcinogenesis. Nutr Cancer 1987; 9:67-71.

45 Hawk ET, Viner JL: Chemoprevention in ulcerative colitis: Narrowing the gap between clinical practice and research (editorial). Ann Intern Med 2001;134:158-160.

46 Shetty K, Rybicki L, Brzezinski A, Carey WD, Lashner BA: The risk for cancer or dysplasia in ulcerative colitis patients with primary sclerosing cholangitis. Am J Gastroenterol 1999;94: 1643-1649.

47 Broome U, Lofberg R, Veress B, Eriksson LS: Primary sclerosing cholangitis and ulcerative colitis: Evidence for increased neoplastic potential. Hepatology 1995;22:1404-1408.
48 Velázquez OC, Seto RW, Choi J, Zhou D, Breen F, Fisher JD, Rombeau JL: Butyrate inhibits deoxycholate-induced increase in colonic mucosal DNA and protein synthesis in vivo. Dis Colon Rectum 1997;40:1368-1375.

49 Weinmann P, Scharffetter-Kochanek K, Forlow SB, Peters T, Walzog B: A role for apoptosis in the control of neutrophil homeostasis in the circulation: Insights from CD18-deficient mice. Blood 2003;101:739-746.

50 Gloria L, Cravo M, Pinto A, de Sousa LS, Chaves P, Leitao CN, Quina M, Mira FC, Soares J: DNA hypomethylation and proliferative activity are increased in the rectal mucosa of patients with long-standing ulcerative colitis. Cancer 1996;78:2300-2306.

51 Meining A, Hackelsberger A, Daenecke C, Stolte M, Bayerdörffer E, Ochsenkühn T: Increased cell proliferation of the gastric mucosa in first-degree relatives of gastric carcinoma patients. Cancer 1998;83:876-881.

52 Milovic V, Teller IC, Faust D, Caspary WF, Stein J: Effects of deoxycholate on human colon cancer cells: Apoptosis or proliferation. Eur J Clin Invest 2002;32:29-34.

53 Shekels LL, Beste JE, Ho SB: Tauroursodeoxycholic acid protects in vitro models of human colonic cancer cells from cytotoxic effects of hydrophobic bile acids. J Lab Clin Med 1996; 127:57-66.

54 Serfaty L, DeLeusse A, Rosmorduc O, Desaint B, Flejou JF, Chazouilleres O, Poupon RE, Poupon R: Ursodeoxycholic acid therapy and the risk of colorectal adenoma in patients with primary biliary cirrhosis: An observational study. Hepatology 2003;38:203-209.

55 Jänne PA, Mayer RJ: Chemoprevention of colorectal cancer. N Engl J Med 2000;342: 1960-1968. 